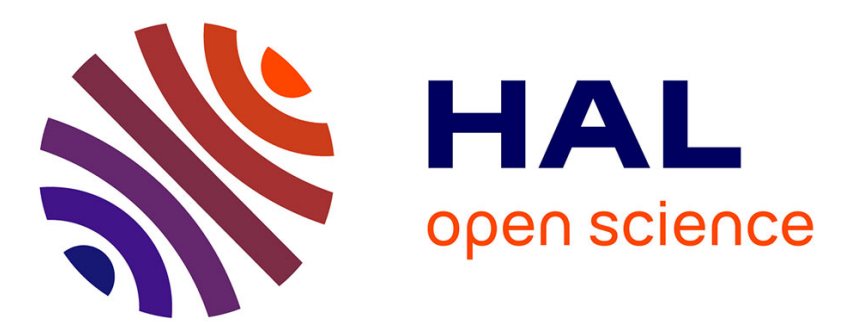

\title{
Analysis of clinically suspected orbital cavernomas
}

Susanne Wiegand, Annette P Zimmermann, Behfar Eivazi, Andreas M

Sesterhenn, Walter Sekundo, Siegfried Bien, Jochen A Werner, Peter J Barth

\section{To cite this version:}

Susanne Wiegand, Annette P Zimmermann, Behfar Eivazi, Andreas M Sesterhenn, Walter Sekundo, et al.. Analysis of clinically suspected orbital cavernomas. British Journal of Ophthalmology, 2010, 94 (12), pp.1653. 10.1136/bjo.2009.177147 . hal-00557362

\section{HAL Id: hal-00557362 https://hal.science/hal-00557362}

Submitted on 19 Jan 2011

HAL is a multi-disciplinary open access archive for the deposit and dissemination of scientific research documents, whether they are published or not. The documents may come from teaching and research institutions in France or abroad, or from public or private research centers.
L'archive ouverte pluridisciplinaire HAL, est destinée au dépôt et à la diffusion de documents scientifiques de niveau recherche, publiés ou non, émanant des établissements d'enseignement et de recherche français ou étrangers, des laboratoires publics ou privés. 


\title{
Analysis of clinically suspected orbital cavernomas
}

\author{
Susanne Wiegand ${ }^{1}$, Annette P. Zimmermann ${ }^{1}$, Behfar Eivazi ${ }^{1}$, Andreas M. Sesterhenn ${ }^{1}$, \\ Walter Sekundo ${ }^{2}$, Siegfried Bien ${ }^{3}$, Jochen A. Werner ${ }^{1}$, Peter J. Barth ${ }^{4}$ \\ 1 Department of Otolaryngology, Head and Neck Surgery, University Hospital Giessen \& \\ Marburg, Campus Marburg
}

2 Department of Ophthalmology, University Hospital Giessen \& Marburg, Campus Marburg

3 Department of Neuroradiology, University Hospital Giessen \& Marburg, Campus Marburg

4 Institute of Pathology, University Hospital Giessen \& Marburg, Campus Marburg

\section{Correspondence to:}

Dr. Susanne Wiegand

Department of Otolaryngology, Head and Neck Surgery

University Hospital Giessen \& Marburg, Campus Marburg

Deutschhausstr. 3

35037 Marburg

Germany

Tel: $+49-6421-5862888$

Fax: $+49-6421-5866367$

e-mail: swiegand@med.uni-marburg.de

Keywords: orbit, cavernoma, lymphangioma, solitary fibrous tumor

Word count: 1781 


\section{Abstract}

\section{Background}

Orbital cavernomas are low-flow vascular malformations which are the most common benign neoplasms of the orbit in adults typically becoming symptomatic in the middle age.

\section{Methods}

The medical records of 6 patients with clinically suspected orbital cavernomas receiving elective surgical excision were analyzed concerning symptoms, physical findings, treatment results and visual outcome. The pathology slides were evaluated and additional immunohistochemical stains were done if necessary to obtain diagnosis.

\section{Results}

Histologic evaluation revealed 3 of 6 cases not being cavernomas although the clinical and macroscopic findings were consistent with orbital cavernomas. Two of them were haemorrhagic lymphangiomas and one was a solitary fibrous tumor.

\section{Conclusions}

Hemorrhagic lymphangiomas and other vascular tumors may mimic orbital cavernomas regarding anamnesis, radiologic and intraoperative findings and gross examination. Therefore exact histologic evaluation is necessary in order to get the correct diagnosis. 


\section{Introduction}

Cavernomas of the orbit are low-flow vascular malformations which consist of endotheliumlined blood-filled cavernous vascular spaces separated by fibrous septa and embedded by a well-delineated capsule.[1] They represent one of the most common primary orbital tumors accounting for approximately $5 \%$ of all mesenchymal orbital neoplasms.[2] Different terms are being used to describe this entity some of which are cavernous haemangioma, cavernous angioma or cryptic vascular malformation.[3] However the term hemangioma should be preserved for rapidly growing tumors of infancy.

Orbital cavernoma typically becomes symptomatic in early middle age by a painless unilateral proptosis but also restriction of eye movements, diplopia and visual impairment are common symptoms.[4] There is no predilection for race or laterality.[3] The typical localization is within the intraconal space, inferior and lateral to the optic nerve.[5] Orbital cavernomas show a female preponderance, their occurrence in children is also reported although in children capillary haemangioma of the orbit is more frequent.[6-7]

MRI seems to be the superior imaging method as it shows features which can typify orbital cavernomas.[3] The typical MRI finding is a well-defined oval mass with a homogeneous signal which is isointense to muscle on T1-weighted MRI scans and hyperintense on T2weighted sequences and progressive filling on Gadolinium-enhanced sequences.[3, 8] Since cavernomas are low-flow malformations intravascular thrombosis is seen in several cases with occasionally associated calcified phleboliths.[9]

Surgery is performed to prevent putative visual damage by increasing pressure of the cavernoma on visually vital structures, to debulk a cosmetically unsightly orbit and to obtain a histological diagnosis, especially in cases where imaging can not predict the kind of tumor. The optimal surgical approach to orbital cavernomas is determined by its location. Lateral orbitotomy provides good access to cavernomas that are located lateral to the optic nerve 
which is the typical location but there are different possible approaches like the medial orbitotomy, the transcranial approach and the transconjunctival orbitomy.[5, 10]

While a large amount of information on the clinical appearance of orbital cavernomas and the appropriate therapeutic strategies is already available,[11] up to now the histological features of orbital cavernomas were less focussed on. The aim of the present study was to analyze the histological features of six lesions displaying typical clinical characteristics of orbital cavernomas.

\section{Patients and methods}

The medical records of 6 patients with clinically suspected orbital cavernomas receiving elective surgical excision were reviewed. We analyzed the clinical data concerning symptoms, physical findings, treatment results and visual outcome. The pathology slides were evaluated and additional immunohistochemical stains were done if necessary.

\section{Results}

Clinical findings

Six patients, four females two males, ranging in age between 7 and 45 years with clinically suspected orbital cavernomas were included in the present study. The left orbit was affected in 4 cases, the right orbit in 2 cases. None of the patients had cutaneous vascular malformations or a family history of cerebral or orbital cavernomas. The indication for surgery was progressive motility disturbance combined with a progressive proptosis and conjunctival chemosis in 2 cases. One patient was operated due to a limitation of eye movements in upgaze and abduction. 2 patients presented with increasing proptosis. In these cases surgery was planned to prevent functional deficits as well as for aesthetic reasons. A loss of 
vision was found in one patient from Eritrea who suffered from a progressive lesion of the orbit for many years. None of the other patients complained a visual acuity loss.

Orbital imaging findings

All patients underwent diagnostic imaging. MRI was performed in 5 patients and CT in 2 patients. MRI and CT described the lesions as well-defined round intra- or extraconal masses. Some degree of enhancement was seen in all patients who received intravenous injections of contrast material (Fig. $1 \mathrm{~A}-\mathrm{C}$ ). In one case an additional angiography was performed (Fig. 1D).

Surgical treatment

In two cases a total resection was performed via lateral orbitomy and in four cases via medial orbitomy. All patients were treated under general anaesthesia. Complete excision of lesions was obtained in all cases reported. The tumors showed typical features of orbital cavernomas, they showed bluish red discoloration and were well encapsulated (Fig. 2A-D).

Postoperative findings

All patients remained without significant complications during the treatment period. Orbital function improved in 5 patients and preoperative diplopia was resolved. There was no change of visual acuity in the patient who already presented with a visual loss.

Pathological findings

In 3 of 6 cases the histology slides disclosed morphologic findings consistent with the diagnosis of an orbital cavernoma (Fig. 3A). These lesions were well circumscribed and demarcated from the surrounding adipose tissue. They showed wide vascular spaces lined by endothelial cells with inconspicuous cytoplasm and small nuclei. Broad fibrous bands harbouring fascicles of smooth muscle surrounded the vascular spaces. Adipose tissue or striated muscle cells were absent from the fibrous septa. 
Two cases turned out to be hemorrhagic lymphangiomas. Histopathological evaluation revealed lesions showing an ill defined outer margin (Fig. 3B). They were composed of irregular vascular spaces lined by small endothelia. The vascular walls were composed of collagen fiber rich fibrous tissue including irregularly arranged fascicles of smooth and striated muscle, adipose tissue and small lymphoid follicles. Proteinaceous fluid and erythrocytes were found in the lumina.

In one case the diagnosis of a solitary fibrous tumour of the orbit was rendered (Fig. 3C). The lesion showed a collagen fiber-rich stroma containing irregularly arranged spindle cells with strong immunohistochemical expression of CD34 and bcl-2. Vessels were numerous, mostly thin-walled and showed a staghorn configuration.

\section{Discussion}

Orbital cavernomas are the most common orbital vascular lesions, followed in frequency by capillary haemangiomas, lymphangiomas and haemangiopericytomas.[12] Typically, they clinically become symptomatic as a slowly progressive painless non-pulsatile unilateral proptosis although bilateral cases have rarely been reported.[13] Although they may occur in children, they are generally tumors of adulthood, with most cases occurring between 30 and 60 years of age. The typical localization is inferior and lateral to the optic nerve.[5]

The pathogenesis of cavernomas and the mechanism of their growth are not known so far. Cavernoma of the orbit is probably a congenital vascular tumor, although some authors claimed an acquired local haemodynamic disturbance as a pathogenic factor.[6] Garner postulated that cavernomas possibly arise by intrapapillary endothelial hyperplasia from preexisting vascular hamartoma. The sluggish vascular flow and ischemia within the tumor might induce endothelial hyperplasia.[14] Orbital cavernomas often grow during pregnancy suggesting their growth to be at least in part being hormone dependent. 
Orbital cavernomas differ from cutaneous and intracranial haemangiomas in both, clinical and morphological features.[14-15] In contrast to cerebral cavernomas orbital cavernomas are encapsulated and firm tumors, whereas cerebral cavernomas are friable nonencapsulated lesions. While orbital cavernomas have regular smooth vessel walls cerebral cavernomas typically have dysplastic, irregular vessel walls which easily rupture.[1] Since the biology of orbital cavernomas has not been studied so far the present study aimed to analyze the histological features of orbital cavernomas.

Six orbital lesions with the typical clinical and macroscopic characteristics of orbital cavernomas were evaluated. All of theses cases showed the typical macroscopic appearance of cavernomas: a dark plum-colored mass with variable trabeculated surface depending on the thickness of the fibrous capsule and septae. However, macroscopic features are unspecific and histologic examination revealed various diagnoses.

In three cases the microscopic evaluation confirmed the macroscopic diagnosis of orbital cavernoma. However, the histologic examination revealed that two of the lesions had the typical microscopic characteristics of hemorrhagic lymphangiomas. In the presented cases the clinical, radiographic and macroscopic features led to the assumption that the lesions were cavernomas.

The computed tomography of the lymphangioma shows a well-defined, enhancing, reasonably homogenous lesion. However, the best imaging method for diagnosing vascular tumors is the MRI. Lymphangiomas typically appear hypointense on both T1- and T2weighted images. Besides, the paramagnetic properties of haemoglobin also make MRI useful in diagnosing lymphangiomas that are blood filled. [16] They often show heterogenous densities with contrast-enhanced MR images. Moreover, the MRI has the advantage of an excellent anatomic resolution which makes it possible to characterize the tumors 
preoperatively more precise especially the position to the optic nerve which is useful in predicting the expected surgical risks. In the CT scan there were no irregular margins or gross multiloculation that may have suggested the true diagnosis. Previous studies also revealed that the sponge-like structure of lymphangiomas often is less well imaged. In the presented cases there also were no radiographic signs favouring the lesions not to be cavernomas.

Histopathologic evaluation revealed typical features of lymphangiomas. Orbital cavernomas are typically being well circumscribed and sometimes encapsulated whereas lymphangiomas display an ill defined outer margin. Moreover, the stroma of lymphangiomas harbours adipose tissue, striated muscle and lymphoid follicles while cavernomas display a purely fibrous stroma. In contrast to cavernomas showing fibrous septa with few smooth muscle cells lymphangiomas display well defined smooth muscle walls.

In one case the mass turned out to be a solitary fibrous tumour. In this case the clinical and macroscopic features also were in accordance with the diagnosis of an orbital cavernoma. However, from the retrospective view, there were some inconsistencies. Cavernomas appear as smoothly marginated masses which are isointense to muscle on T1-weighted MR images and hyperintense on T2-weighted sequences. Progressive and total homogenous filling up after initial patchy enhancement on gadolinium-enhanced MRI is a pathognomic sign of orbital cavernomas. This was also true for the presented cases which turned out to be cavernomas. The MRI of the patient with the solitary fibrous tumor showed heterogenous densities which are no typical radiological aspects of cavernomas. This finding may have led one to the correct diagnosis. However, angiography showed a well-perfused lesion. Finally, histopathologic evaluation resulted in the diagnosis of a solitary fibrous tumor. Solitary fibrous tumurs of the orbit harbour vessels with a hemangiopericytoma like vascular pattern indicating the close relation of these lesions.[17] However, the vascular lumina are smaller 
and staghorn-like compared with those of cavernomas and lymphangiomas which was also true in this case.

The present analysis shows that the diagnosis of orbital cavernoma may not always be straightforward. In 3 of 6 cases both the preoperative diagnosis and the initial operative findings were consistent with the diagnosis cavernomas. Especially the imaging features of the patients with lymphangiomas simulated cavernomas very well. Moreover the lesions showed typical macroscopic findings of cavernomas like a defined capsule and a soft tissue texture.

Therefore, these findings underline the value of a precise histologic evaluation with immunohistochemical staining to distinguish cavernomas from other vascular tumors. The most important differential diagnosis of cavernoma seems to be hemorrhagic lymphangioma. As lymphangiomas may display a locally aggressive nature,[18] and severe complications such as infection and bleeding[19] the precise distinction of vascular tumors of the orbit may significantly influence the therapeutic approach and thus patients' prognosis.

\section{Licence for Publication}

The Corresponding Author has the right to grant on behalf of all authors and does grant on behalf of all authors, an exclusive licence on a worldwide basis to the BMJ Publishing Group Ltd, and its Licensees to permit this article (if accepted) to be published in BJO editions and any other BMJPGL products and to exploit all subsidiary rights, as set out in our licence.

\section{Competing Interest}

None declared. 


\section{References}

1 Hejazi N, Classen R, Hassler W. Orbital and cerebral cavernomas: comparison of clinical, neuroimaging, and neuropathological features. Neurosurg Rev 1999;22:28-33.

2 Ohtsuka K, Hashimoto M, Suzuki Y. A review of 244 orbital tumors in Japanese patients during a 21-year-period: origins and locations. Jpn J Ophthalmol 2005;49:49-55.

3 Thorn-Kany M, Arrue P, Delisle MB, et al. Cavernous haemangiomas of the orbit: MR imaging . J Neuroradiol 1999;26-86.

4 Schick U, Dott U, Hassler W. Surgical treatment of orbital cavernomas. Surg Neurol 2003;60:234-244.

5 O’Mahony D, O`Neill E. Recurrent proptotic diplopia due to congestive expansion of cavernous haemangioma with relapsing right-sided cardiac failure. Postgrad Med $\mathrm{J}$ 1999;75:607-618.

6 Harris GJ, Jakobiec FA. Cavernous haemangioma of the orbit. In: Jakobiec FA, ed. Ocular and adnexa tumors. Birmingham, AL: Aesculapius, 1978:741.

7 Maheshwari R, Thool A. Orbital cavernous hemangioma of childhood. Indian J Ophthalmol 2007;55:313-315.

8 Bilaniuk L. Orbital vascular lesions: role of imaging. Radiol Clin North Am 1999;37:169-183.

9 Acciarri N, Padovani R, Giuloni M, et al. Intracranial and orbital cavernous angiomas: a review of 74 surgical cases. Br J Neurosurg 1993;7:529-539. 
10 Cheng JW, Wei RL, Cai JP, et al. Transconjunctival orbitotomy for orbital cavernous haemangiomas. Can J Ophthalmol 2008;43:234-238.

11 Scheuerle AF, Steiner HH, Kolling G, et al. Treatment and long-term outcome of patients with orbital cavernomas. Am J Opthalmol 2004;138:237-244.

12 Günalp I, Gündüz K. Vascular tumors of the orbit. Doc Ophthalmol 1995;89:337-345.

13 Sullivan TJ, Aylward GW, Wright JE, et al. Bilateral multiple cavernous haemangiomas of the orbit. Br J Ophthalmol 1992;76:627-629.

14 Garner A. Cavernous haemangiomas of the orbit. A consideration of its origin and development. Orbit 1988;7:149-156.

15 Challa VR, Moody DM, Brown WR. Vascular malformations of the central nervous system. Neuropathol Neurol 1995;54:609-621.

16 Gündüz K, Kurt RA, Erden E. Well-circumscribed orbital venous-lymphatic malformations with atypical features in children. Br J Ophthalmol 2009;93:656-659.

17 Goldsmith JD, van de Rijn M, Syed N. Orbital hemangiopericytoma and solitary fibous tumor: a morphologic continuum. Int J Surg Pathol 2003,9:295-302.

18 Eivazi B, Ardelean M, Bäumler W, et al. Update on hemangiomas and vascular malformations of the head and neck. Eur Arch Otorhinolaryngol 2009;266:187-197.

19 Wiegand S, Eivazi B, Barth PJ, et al. Pathogenesis of lymphangiomas. Virch Arch 2008;453:1-8. 


\section{Legends to figures}

1A. MRI finding of an orbital cavernoma showing a well-defined retrobulbar oval mass with a homogenous signal.

1B. Preoperative CT scan showing a well-defined oval mass with a homogenous signal, histology revealed this lesion to be a lymphangioma.

$1 \mathrm{C}$ and 1D. Preoperative MRI and angiography showing a high-perfused lesion which turned out to be a solitary fibrous tumor.

2A. Macroscopic appearance of the resected cavernoma of the orbit showing a darkcoloured mass with a fibrous capsule and a trabeculated appearance on its surface.

2B. Macroscopic appearance of the resected lymphangioma of the orbit showing a darkcoloured mass with a fibrous capsule.

2C. Preoperative findings in the patient with the solitary fibrous tumor.

2D. Intraoperative findings: a dark-coloured mass with a fibrous capsule and a trabeculated appearance on its surface.

3A. Histologically the cavernoma shows wide vascular spaces filled with blood surrounded by broad fibrous bands harbouring fascicles of smooth muscle.

3B. Histologically the lymphangioma is composed of irregular vascular spaces filled with proteinaceous fluid and few erythrocytes. Smooth and striated muscle as well as adipose tissue and lymphoid follicles are found in the irregular vessel walls. 
3C. Photomicrograph of the solitary fibrous tumor: thin-walled vessels disclosing a staghorn appearance surrounded by spindle cells arranged in irregular fascicles. 

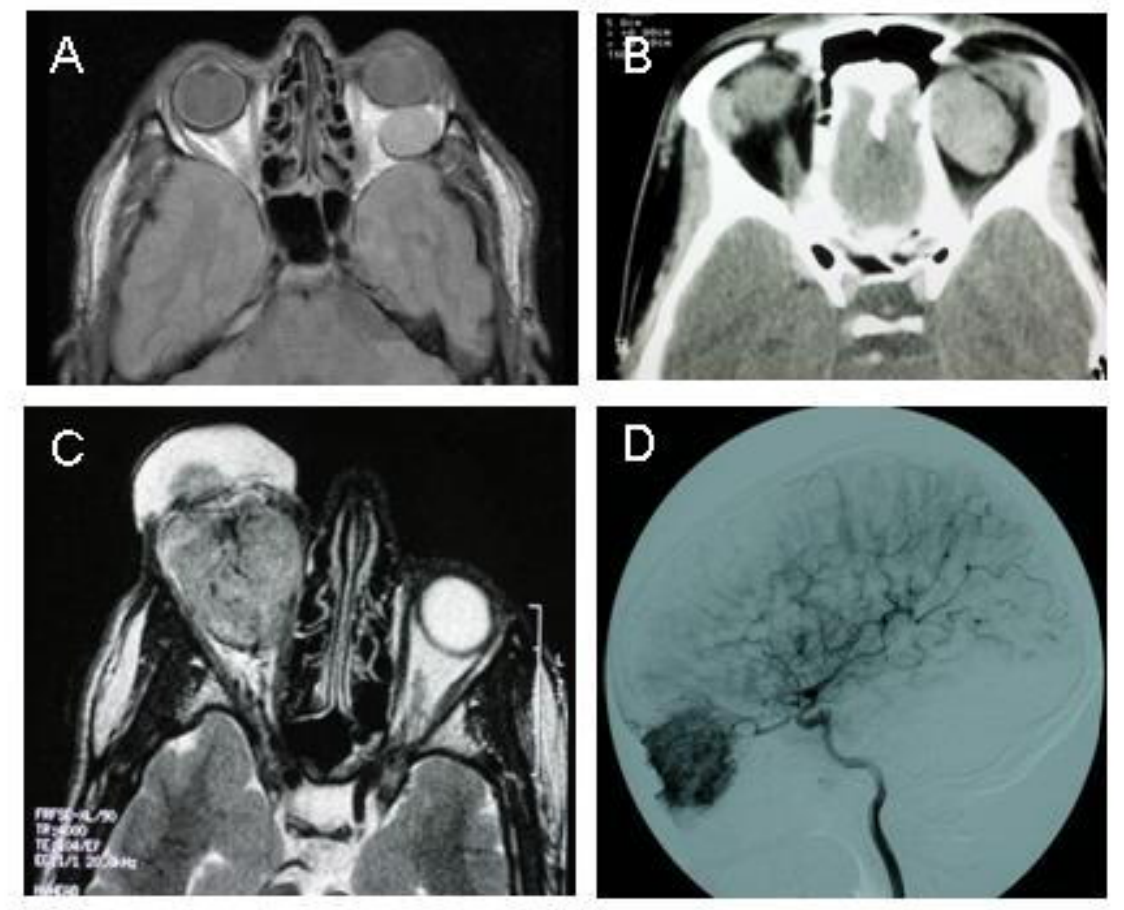


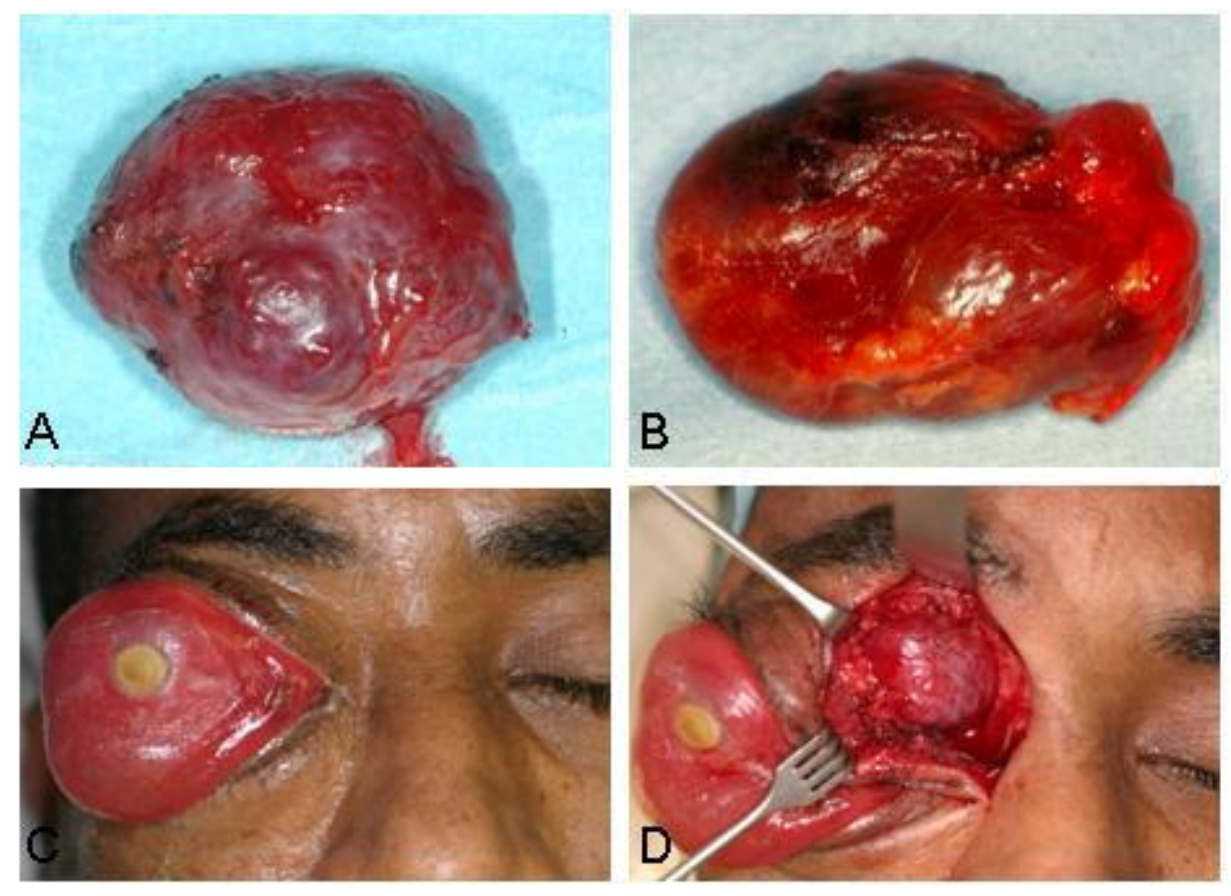



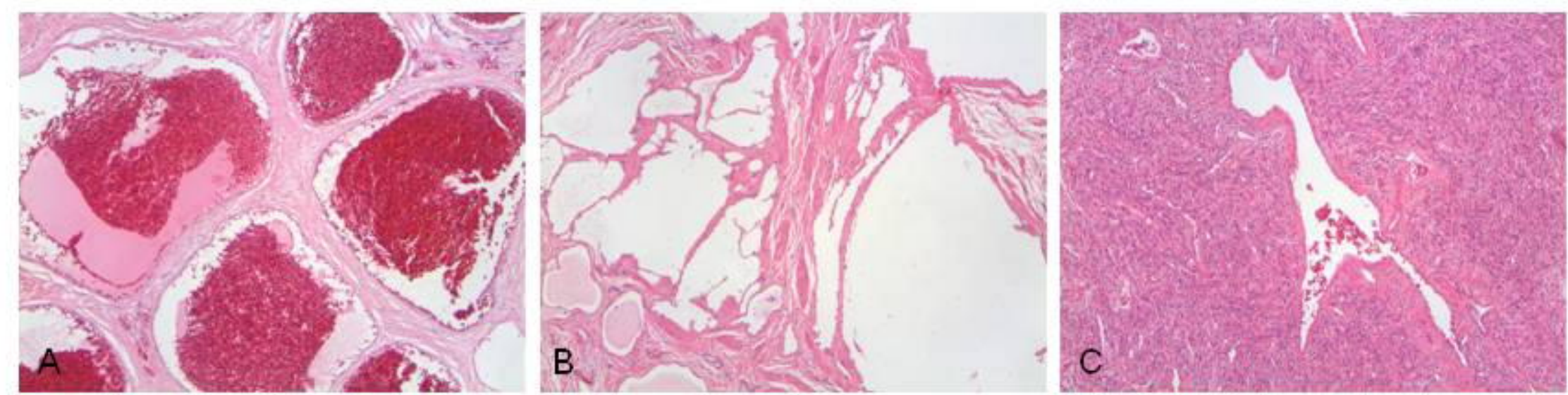